\title{
WITHIN-COUNTRY INEQUALITY AND THE MODERN WORLD-SYSTEM: A THEORETICAL REPRISE AND EMPIRICAL FIRST STEP
}

\author{
Matthew C. Mahutga \\ Department of Sociology \\ University of California, Riverside \\ matthew.mahutga@ucr.edu \\ Roy Kwon \\ Department of Sociology \\ University of California, Riverside \\ roykwon@gmail.com \\ Garrett Grainger \\ Department of Sociology \\ University of Wisconsin, Madison \\ ggrainger@wisc.edu
}

\begin{abstract}
This article calls for a renewed investigation of the world-system position-inequality link. We begin by outlining two general types of causal mechanisms through which a country's position in the world-system should impact the distribution of income within it. The first type impacts inequality indirectly by conditioning the developmental process, and call for conceptual and empirical models of inequality that account for the link between world-system position and economic development. The second type impacts inequality directly through processes that are more or less unobservable because they change over time or belie cross-nationally comparative indicators, and can thereby be captured by direct measurements of world-system position itself that stand in for varying or unobservable causal processes. We then analyze five measures of world-system position to identify which, if any, provides the most useful association with income inequality. Our findings suggest that the classic measure of Snyder and Kick (1979) provides the strongest association. We conclude by suggesting fruitful directions for future research.
\end{abstract}

\section{INTRODUCTION}

General sociological theories of within country inequality can be roughly divided into two types. The first type begins with independent nation-states as the unit of analysis, between which differential stages along a relatively homogenous developmental path explain differences in within-country inequality. The second type begins with an interdependent international division of labor and anarchic world-polity as the appropriate unit of analysis, within which cross-national differences in income inequality are a function of positional variation in the hierarchically ordered world-system. Both schools of thought have produced a large body of empirical work in 


\section{WITHIN-COUNTRY INEQUALITY AND THE WORLD-SYSTEM 280}

sociology. Within this body of work, developmental processes have been shown to bear fairly robust relationships with income inequality (Nielsen 1994; Nielsen and Alderson 1995; Lee 2005). On the other hand, the association between world-system position and various forms of dependency have been much disputed, and empirical tests of the world-systems perspective have become infrequent (e.g. Alderson and Nielsen 1999; Beer and Boswell 2002; Lee et al. 2007; Nolan 1983; Weede and Kummer 1985).

Yet, our review of the literature suggests that a renewed investigation of the worldsystem position-inequality link is warranted, and this article builds a foundation for such an endeavor by accomplishing two goals. One of our immediate goals is to re-introduce worldsystemic dynamics as a principal explanation for cross-national variation in within-country inequality. Answering the call for world-systems scholars to pay better attention to the country level processes through which world-system dynamics impact inequality (Alderson and Nielsen 1999), our review of the literature suggests two general causal pathways in which a country's position in the world-system should impact its level of income inequality. In the first causal pathway, world-system dynamics increase inequality indirectly through their impacts on developmental processes, suggesting the need for conceptual and empirical models of inequality that account for the link between world-systems position and the development path. In the second pathway, world-system dynamics increase inequality directly via processes that are more or less unobservable, either because the precise mechanisms change over time in concert with the evolution of the world-system or they belie the collection of cross-nationally comparative data, which suggests that direct measures of world-system position can stand in for a number of unobservable processes.

Our second main goal is empirical. We review the literature on the world-system position-inequality link and find that the results are at best mixed on this topic and almost exclusively focused on a single measure of world-system position. We then discuss two broad approaches to the measurement of positionality in the world-system-those based on relational data and network analysis and those based on various country attributes - and identify five different measures that become the focus of the empirical investigations that follow. We then select these five operationalizations as representatives of the most recent and refined indicators from the research programs initiated by Snyder and Kick (1979), Nemeth and Smith (1985), Clark and Beckfield (2009), Arrighi and Drangel (1984) and Kentor (2000) in order to identify the measurement strategy that produces the most theoretically consistent and "robust" association with income inequality as a foundation of future inquiry.

The empirical core of the paper compares the five measures of world-system position with respect to their ability to estimate world-systemic variation in income inequality in a manner that is consistent with the theory. As such, we present evidence based on bivariate descriptive statistics and model-based estimates that control for economic development across 5 sets of sample restrictions designed to deal with the differences in both country and temporal coverage between measures. Our results suggest rather definitively that (1) world-system dynamics do seem to matter for income inequality though (2) network based approaches are somewhat stronger predictors than are attribute based approaches, and (3) the Snyder and Kick (1979) version that was subsequently updated (Bollen 1983; Bollen and Appold 1993) may provide the best starting point for future causal investigations of the world-system position-inequality link. We close by calling for a renewed inquiry into the world-system position-inequality link and suggest fruitful ways to pursue it. 


\section{THE WORLD-SYSTEM POSITION-INEQUALITY LINK}

World-system explanations for cross-national variation in income inequality begin with the notion that the whole world-system "is the basic unit of analysis and the entity whose properties ultimately explain outcomes" for the smaller units that make up the system (Mahoney 2004: 461; see Chase-Dunn 1998; Wallerstein 1989 and critique by Skocpol 1977). At the highest level of abstraction, variation in inequality across zones of the world-system is thought to reflect the working of the system itself, which functions as an interdependent international division of labor governed by an anarchic state-centric polity (e.g. Wallerstein 1989). In short, levels of income inequality in one particular country are not independent of those in others, they are related through system level mechanisms that create varied outcomes across world-system positions.

Yet, identifying the precise mechanisms that produce variation in the level of inequality across world-system positions has been a particularly vexing problem for scholars of inequality. As two prominent scholars note, world-system analysts should do a better job at "drawing out the causal links between external factors [world-system position] and internal outcomes [income inequality] in a more systematic fashion (Alderson and Nielsen 1999: 627). Our review of the literature on the relationship between world-system position and income inequality suggests two types of discernable mechanisms. The first type includes indirect mechanisms that work through economic development: world-system position $\rightarrow$ development $\rightarrow$ inequality. The second type includes political-economic processes that are more or less unobservable in any systematic way, including capitalist class alliances between countries, overt and covert state-originated political interventions between core and periphery, and the entrenchment of outward oriented economic interests in peripheral countries. As we discuss below, some of these mechanisms are unobservable because their specific spatio-temporal content varies over time in concert with the evolution of the system itself, while others are unobservable due to inherent difficulty in compiling cross-nationally comparative data for them. In what follows, we review both types of mechanisms in order to demonstrate that cross-national variation in world-system positionality should matter for the same variation in income inequality, at least in theory.

\section{World-System Dynamics and Economic Development}

Variables capturing dimensions of the concept of economic development are among the most established correlates of income inequality in cross-national analyses. The pioneering work of Simon Kuznets (1955) postulated a curvilinear link between development and inequality that is explained primarily by wage differences that exist between a country's agricultural and modern sectors. In particular, Kuznets noted that countries at lower stages of development typically have relatively large segments of the labor force in the agricultural sector, where wages are both low and homogenous. The slow process of industrialization increases inequality at first through sector dualism: inequality arising from the higher relative wages in the manufacturing vis-à-vis the agricultural sector, and because inequality is less equally distributed within the manufacturing sector.

However, once a significant portion of the labor force migrates to the manufacturing sector, inequality begins to fall as a higher relative proportion of the labor force enters into the manufacturing sector, homogenizing the sectoral composition of the labor force and gradually negating the wage gap between the agricultural and manufacturing sectors. In addition to sector 


\section{WITHIN-COUNTRY INEQUALITY AND THE WORLD-SYSTEM 282}

dualism, Kuznets and others highlight the role of education and the demographic transition as explanations for the development $\rightarrow$ inequality link: as countries develop from traditional (agricultural) to modern (industrial) economies, education enrollment rates and life expectancy increases while fertility declines (Nielsen 1994). The spread of education tends to reduce the wage premium to skilled labor, while the demographic transition slows the growth of the nonworking age population and is often associated with an increase in the status of women.

While Kuznets' model is premised on the development of the modern (or manufacturing) sector, world-system theorists suggest that the sectoral composition of the national economy is a function of its position in the world-economy (e.g. Arrighi and Drangel 1984; Arrighi et al. 2003; Chase-Dunn 1998; Wallerstein 1974; cf. Bollen and Appold 1993). That is, the world-system perspective suggests that a country's developmental process is conditioned by the position it occupies in the world-system as core countries contain the industries and production processes that are at the leading edge of the capitalist world-economy. While the concrete forms of these economic activities change over time-i.e. mechanized textile manufacturing was once at the leading edge but has now become "peripheralized"- the key point is that advanced economic activities remain in the core, where "...organizational forms of production are much more complex" (Bornschier and Chase-Dunn 1985: 127). In terms of the dynamics highlighted by Kuznets and others, core countries are more likely to possess a modern sector capable of absorbing the bulk of the labor force, both because of greater organizational complexity and greater dynamism in the long term (e.g. Arrighi and Drangel 1984; Chase-Dunn and Grimes 1995).

The counterpart to this historical dynamic is that activities contained within the boundaries of the periphery of the world-system are the least advanced. Modern sectors that do develop in peripheral societies are often subject to extended periods of crisis and contraction, if not outright subjugation (O'Hearn 1994). Thus, extended periods of either contraction or subjugation are likely to inhibit the modern sector's ability to absorb a significant proportion of the labor force, potentially resulting in structural underemployment and large reserves of surplus labor. As a result, differences in the composition of the labor market between core and periphery can remain fixed in the long-term (with fluctuations in the short-term: Arrighi and Drangel 1984), creating differences in income inequality therefore (cf. Firebaugh 2003).

Education and the demographic transition tend to decrease inequality in the long run, but they are also patterned by world-system dynamics, at least in theory. For example, increases in

education are in part a function of state capacity, where enrollment rates are higher in countries where states have enough internal stability to manage a national educational system and the resources to do so. Moreover, the extent to which countries contain a "stable set of authority relations which give rights of the regulation and control of activities of its population to the state" varies tremendously across positions in the world-system (e.g. Rubinson 1976: 641-2; Bollen 1983). Likewise, the demographic transition is also in part a function of world-system dynamics, since the demographic transition occurs as countries grow and growth is impacted by worldsystem dynamics (e.g. Snyder and Kick 1979). As two prominent world-systems theorists propose by way of summary, "it is not a low level of development that creates high inequality, but rather peripherality in the world division of labor..." (Bornschier and Chase-Dunn 1985: 23). 


\section{World-System Dynamics and Unobservables}

Another type of causal pathway for the world-system position-inequality link involves processes that are more or less unobservable, particularly with extant cross-nationally comparative data. As articulated in a seminal article by Mahoney, unobservables constitute the "original movers or "ultimate causes" for general theory (2004: 461). In the rubric of worldsystems theory, interstate capitalist competition is the primary mover of outcomes, but the concrete form in which this struggle manifests varies over time at the level of the system and across the tripartite zones of the world-system structure. In other words, capitalist classes are spatially embedded in states and compete for gains from the capitalist mode of production, but these classes and states have unequal amounts of resources at their disposal and differential material bases on which to compete. Furthermore, insofar as the concrete forms in which the gains from capitalist production can be reaped changes over time, many world-system mechanisms must be "empirically underspecified, exist outside specific spatial and temporal boundaries, and cannot be directly observed," at least until after the fact (Mahoney 2004: 461).

One example is alliances between ruling classes in core and non-core countries. These alliances impact the structure of the economy, and thereby the developmental processes outlined above. For example, Rubinson (1976) notes that economic choices in non-core societies are made by a small "elite whose predominant interests have been tied to foreign economic actors through mutual interests in the control of production for export," which leads to the decline of indigenous economic actors and thereby restricts the size of the modern sector (643; also see Chase-Dunn 1998; O’Hearn 1994).

Moreover, inter-societal class relations can also impact the redistribute capacity of the nation-state and levels of democracy in non-core countries. While core countries tended to experience rising levels of participatory democracy over the course of economic development, world-system scholars believe that elites in peripheral countries are able to quell efforts to mobilize for political integration among lower classes and "successfully resist demands for redistribution" (Bornschier and Chase-Dunn 1985: 23; also see Rubinson 1976; Rubinson and Quinlan 1977). Successful efforts to redistribute that do emerge in peripheral countries may be shallow or transitory. On one hand, as the events surrounding the 2004 removal of Jean-Bertrand Aristide in Haiti illustrate, peripheral states are weak vis-à-vis international institutions and stronger states in the core (Farmer 2004). On the other hand, the fragmented class structure of peripheral states limits the domestic legitimacy of any regime, which increases the likelihood of instability (Chase-Dunn 1998; McMichael 1996; Rubinson 1976). Thus, while democratic societies give voice to lower classes and thereby generate more equal distributions of income (e.g. Hewitt 1977; Muller 1988; c.f. Lee 2005; Simpson 1990), non-core countries are less likely to develop the capacity for sustained redistributive policies and democratic institutions than core countries (Bollen 1983; 1987).

Finally, one prominent argument for persistent variation in the distribution of income between zones of the world-system is a political one that is logically equivalent to structural functionalist explanations in that the existence of subordinated world-system zones-and the higher levels of inequality within them-is necessary for the reproduction of capitalist social relations at the system level (e.g. Chase-Dunn 1998). In the first case, the extra surplus value extracted from peripheral countries gets distributed among core workers and capitalists, and thereby decreases inequality and the probability of class-based political conflict in the core. In 


\section{WITHIN-COUNTRY INEQUALITY AND THE WORLD-SYSTEM 284}

the second case, competitive rivalries over access to peripheral areas reproduce both a multicentric core zone (rather than an imperial core-wide state) as well as a subordinated periphery. Both inter-core capitalist competition and a peripheral zone are regarded as "necessary structural bases of capitalism," suggesting in turn that persistent differences in income inequality between zones are a natural outcome of this structure (Chase-Dunn 1998: 248).

In all these cases, the primary causal process for variation in income inequality between core and periphery involves either political intervention or economic exploitation by the core. One of the primary ways that world-system scholars have historically attempted to operationalize this mechanism has been with direct measures of foreign capital penetration under the assumption that one or more of these mechanisms was operative in non-core countries with a significant presence of foreign capital. Yet, the nature of FDI has changed significantly over the latter part of the $20^{\text {th }}$ century, where the bulk of FDI now flows between core countries and informal subcontracting relationships now supplement or supplant the proprietary capitalistic relations inherent to FDI flows into peripheral countries (eg. Alderson and Nielsen 1999; Kollmeyer 2009; Mahutga 2011).

Moreover, the set of peripheral countries selected for political intervention and/or exploitation by core states varies over time with shifts in the economic sectors that constitute the productive frontier. In the early $19^{\text {th }}$ century, textile production was the leading edge of the capitalist world economy so that sites of cotton cultivation and textile production were often targets of political and economic interference by core states (e.g. O'Hearn 1994). Yet, by the early $20^{\text {th }}$ century, mineral deposits including metals and carbon based fuels became the focal points of economic expansion which again shifted to labor intensive manufacturing by the late $20^{\text {th }}$ century. In this way, the set of peripheral countries at the center of core interventions-and the form these interventions took-changed over time (e.g. Bunker and Ciccantell 2000). Thus, many operationalizations of world-system dynamics with measures of "dependency," including foreign capital penetration and concentration, vertical trade, raw material exports, commodity concentration, trade partner concentration, etc., can at best capture specific spatio-temporal moments of the spatially uneven capitalist competition and exploitation that are the prime movers of the variation in income inequality across zones of the world-system.

In sum, world-system dynamics matter for cross-national differences in income inequality, at least in theory. These dynamics impact inequality through at least two causal pathways. First, world-system dynamics create persistent cross-national differences in levels of economic development, including levels of income and domestic economic structure, which in turn create divergent levels of income inequality. Second, world-system dynamics impact inequality directly through processes that are more or less unobservable and/or vary over time. In what follows, we review previous findings on the world-system position-inequality link in order to make our case that a renewed inquiry is warranted, and take the initial step of identifying which among the many operationalizations of world-system position generates the most theoretically consistent and robust association with income inequality.

\section{PREVIOUS FINDINGS AND OUR APPROACH}

Extended derivations of a theoretical proposition relating world-system dynamics to income inequality are limited in the literature (Bornschier and Chase-Dunn 1985; Nolan 1983). 
Bornshcier and Chase-Dunn (1985) provide the most succinct proposition that is in direct conversation with Kuznets (126-129). Bornshchier and Chase-Dunn suggest that world-system position bears a negative association with income inequality with the caveat that fully integrated peripheral countries should have higher inequality than horticultural and simple or advanced agrarian countries that are not fully integrated into the world-system. Empirical results for the relationship between world-system position and income inequality have been mixed. Yet, a review of the literature suggests it is difficult to assess the extent to which this is a function of the weakness of the theory or rather the great number of ways it has been operationalized and the tendency to conflate various measures of "dependency" with position in the world-system (see Beer and Boswell 2002; Bollen 1987; Bornschier et al. 1979; 1978; Bornschier and Chase-Dunn 1985; Lee et al. 2007; Nolan 1983; Rubinson 1976; Weede and Kummer 1985).

For example, Rubinson (1976) draws compelling arguments for the world-system position -inequality link related to class formation, the organization of production/occupational structure and class relations. The empirical evidence presented by Rubinson largely confirms the hypothesis, but world-system positionality is operationalized as government revenue to GDP. Likewise, the foreign capital penetration (PEN) literature tends to find that PEN increases income inequality (e.g. Alderson and Nielsen 1999; Beer and Boswell 2002; Bornschier et al. 1978; 1979; Bornschier and Chase-Dunn 1985). Yet, while PEN dynamics might clearly be implicated in world-system dynamics, they are not identical (e.g. Evans 1979; Snyder and Kick 1979). Moreover, initial investigations of PEN were based primarily on its ability to proxy for "peripherality" in the world-system (Bornschier and Chase-Dunn 1985), and we have already suggested that various forms of dependency represent temporally fleeting means by which to capture world-system mechanisms. Thus, it is difficult to assess the direct effects of worldsystem position from studies that evoke either "dependency" covariates or indirect proxies for world-system position (also see Beer and Boswell 2002). ${ }^{1}$

Studies that assess the world-system position-inequality link directly tend to find a negative linear association between inequality and world-system position-core countries have the lowest inequality, followed by semiperipheral and peripheral countries, but these results are often fragile or disputed. One of the first studies (Nolan 1983) found significant and linear differences between the core, semiperiphery and periphery in bivariate regressions, but the association became insignificantly curvilinear after controlling for economic development ${ }^{2}$, and even this was challenged on methodological grounds (Weede and Kummer 1985) but then rebutted (Bollen 1987). An even larger number of studies find that world-system position bears a negative linear association that becomes null after controlling for level of economic development or other variables that capture some of the developmental processes outlined above (Lee 2005; Lee et al. 2007), though one only included an indicator of core status (Alderson and Nielsen 1999).

\footnotetext{
${ }^{1}$ Still, as our initial discussion of the world-system position $\rightarrow$ development link implies, it is clear that FDI penetration might play a role in explaining some of the variation in inequality between world-system zones, and was precisely articulated as such in earlier work (e.g. Chase-Dunn 1998: 236-7). We return to this discussion in the conclusion.

${ }^{2}$ The semiperiphery had an insignificantly lower level of inequality than the core, contrary to expectations that might be consistent with Kuznets, while the peripheral inequality remained significantly higher than the core in the full models.
} 


\section{WITHIN-COUNTRY INEQUALITY AND THE WORLD-SYSTEM 286}

One explanation for the fragility of previous findings might be the chosen indicator of world-system position. Published tests of the world-system position-inequality link almost uniformly use a version of the Snyder and Kick's (1979) network based world-system measure that was subsequently updated (Bollen 1983; Bollen and Appold 1993), but there are currently many more available indicators of world-system position. Thus, the circumscribed goal of the present research is to identify which among the multiple available measures of world-system position seems to provide the most theoretically consistent and strongest association with income inequality, even when levels of economic development are at least partially controlled.

One of the major dividing lines between types of world-system indicators is that between measures based on country attributes (e.g. Arrighi and Drangel 1986; Babones 2009; Kentor 2000) and those based on international relationships (e.g. Boyd et al. 2010; Clark and Beckfield 2009; Mahutga 2006; Mahutga and Smith 2011; Nemeth and Smith 1985; Snyder and Kick 1979). Indeed, an important middle range debate within the world-system community revolves around the appropriateness of one type over another. For example, it is clear that one of the more widely accepted aspects of the world-system perspective is that it presupposes a shift "from a concern with the attributive characteristics of states to concern with the relational characteristics of states" (Wallerstein 1989:xi). Thus, one side of this debate has argued that social-network based measures are superior because "attribute data measure select consequences of structural pattern...but they are neither descriptions nor analyses of the structure itself" (White and Breiger 1975:68). While such claims are not infrequent, others suggest "the contention that network measures are superior to attribute measures has been argued but not demonstrated" (Chase-Dunn and Grimes 1995: 398). Thus, we hope to bring some empirical evidence to bear on this methodological issue by comparing the association between world-system position and inequality across the attribute/network-based divide.

\section{Network Types}

Network analyses of the world-system are becoming more frequent, and have been discussed at length in Lloyd et al. (2009). We refer the interested reader to that article for a more detailed discussion. The first effort to take seriously the notion that the world-systems perspective is a fundamentally relational theory was that of Snyder and Kick (1979), who analyzed four relations-international trade, military interventions, diplomatic exchanges and conjoint treaty memberships - with data from the early 1960s. Snyder and Kick (1979) used a role and position analysis based on structural equivalence to identify the global structure and the individual positions countries occupy within that structure for 118 countries. Later updates increased the sample size to 127 countries (Bollen 1983 and Bollen and Appold 1993). As noted above, this is the most often analyzed measure of world-system position (e.g. Alderson and Nielson 1999; Lee 2005; Lee et al. 2007).

After Snyder and Kick, Nemeth and Smith (1985) initiated another line of research designed to identify the world-system structure and the individual position that countries occupy within it. Three major features distinguish the work owing to Nemeth and Smith (1985). First, they analyze multiple trade relationships in which each individual relation represented different types of commodities. Second, this line of research was also based on the analysis of roles and positions from SNA, but eventually integrated a more general type of equivalence-regular equivalence (Smith and White 1992; Mahutga 2006). Third, this line of research is longitudinal, 
initially covering a period of 1965-1980 and more recently through 2000. The most recent research expanded a rather small sample size from Smith and White (1992) and Mahutga (2006) to produce a measure of the overall structure and country positions for 94 countries at five points in time, from 1965 to 2000 (Mahutga and Smith 20111). Unlike the other two network based measures, Mahutga and Smith (2011) produce both categorical and continuous measures of world-system position.

The most recent network based measurement strategy is that of Clark and Beckfield (2009). Unlike Snyder and Kick (1979) and the line owing to Nemeth and Smith (1985), Clark and Beckfield combine Borgatti and Everett's (1999) continuous measure of "coreness" with a categorical analysis in which a block model was constructed by (1) permuting the rows and columns of a matrix of dichotomized total trade according to the rank order of continuous coreness and (2) identifying the categorical position of core as consisting of the group of countries with above average interaction, the semiperipheral position as consisting of a group of countries with exactly average interaction and the peripheral group as consisting of the group of countries with below average interaction, where average was a function of the matrix as a whole. Using average trade flows from 1980-1990, Clark and Beckfield generate a time-invariant trichotomous measure of world-system position on 140 countries. ${ }^{3}$

\section{Attributional Types}

Within the community of world-system analysts, Arrighi and Drangel's (1986) classification of world-system position based on GNP per capita is classic. Recently, Salvatore Babones refined

\footnotetext{
${ }^{3}$ One reviewer noted that there are a number of network based measures of world-system position that are omitted from our analysis, including the work of Van Rossem (1996), Smith and White (1992), Mahutga (2006), the original version of Snyder and Kick (1979), Nemeth and Smith (1985), Kick et al. (2001) and Clark (2010). Our omission of many of these was strategic, and involved considerations of (1) the fact that many of these measures are iterations of a single methodological approach from which we selected the most recent/refined iteration and/or (2) some of them do not provide a sufficient number of yearly observations. Thus, for example, the positions identified by Nemeth and Smith (1985) (NS), Smith and White (1992) (SW) and Mahutga (2006) (M06) were based on the same multi-relational data as Mahutga and Smith (2011) (MS). However, MS used a significantly larger sample size than any of the previous publications (both NS and SW only analyze data from 1965 to 1980 on just over 70 cases, M06 covers the whole period but on only 52 cases), and is based on a more theoretically justifiable equivalence criterion than is NS (see Lloyd et al. 2009). Likewise, Kick's (2001) measure is a reiteration of the same CONCOR based structural equivalence measure of Snyder and Kick (1979), which was subsequently improved upon by Bollen (1983) and Bollen and Appold (1993). Van Rossem's measure was based on data collected in the late 1990s, and thus would preclude well over 80 percent of the Gini observations from analysis. Thus, our omission of Van Rossem and selection of the expanded and updated measure seems to allow us to represent that lineage with the most refined variable. Finally, Clark's (2010) measure was published after the initial submission of this article and the pattern of missing cases between it and the 52 models estimated here would require the estimation of entirely new sample restrictions. Thus, we simply estimated unreported versions of the common sample restriction (restriction B) adjusted to account for the missing data in Clark (2010). These results were substantively identical to those reported below in terms of the overall strength of world-system position-inequality association. The continuous measure of Clark (2010) was significantly negative and slightly larger than the other two continuous measures, but the fit was not as high as that of SK. Like Clark and Beckfield (2009), it only covers the period since 1980.
} 


\section{WITHIN-COUNTRY INEQUALITY AND THE WORLD-SYSTEM 288}

this study and extended it forward in time to create a trichotomous measure of world-system position for up to 181 countries from 1960 to 2000 (Babones 2009). In Babones (2009), the distribution of GNP per capita is distinctly trimodal, where core countries are located in the richest mode, semiperipheral countries are located in the intermediate mode, and peripheral countries are located in the poorest mode.

Another classic approach is that of Kentor (2000). Kentor creates a continuous index of coreness based on two indicators of economic power (GDP and GNP pc) and one measure of coercive power (total military expenditures). These variables are first Z-score standardized and then summed to measure a country's position in the global hierarchy. Because this measure of position is based on Z-scores, overtime comparisons are only possible if the sample of countries on which it is based remains unchanged. Thus, in order to maximize the temporal variation, we used a recently compiled data set that covers 60 countries from 1965 to 2005 (Kentor et al. 2010). Below we discuss other sources of data and methodological issues that bear on the analyses presented here.

\section{DATA}

\section{Gini Coefficient}

Previous studies recognize issues of comparability in available estimates of income inequality. Many earlier studies used the Deininger and Squire (1996) "high quality" database, which includes a maximum of 682 (those deemed as acceptable by Deininger and Squire) Gini observations that differ on the reference unit (e.g. household or individual) and the definition of income (e.g. gross or net income) and on the overall quality of measurement. Differences in definition can have a substantial impact on the estimate of income inequality (Deininger and Squire 1996). As a result, researchers face a dilemma: restricting the observations to those with high quality and comparable Ginis substantially reduces the sample size, and including larger number of Ginis reduces comparability and/or quality. Thus, earlier studies resolve this by analyzing only high quality estimates and correct for differences in definition by including carefully constructed dummy variables for the various categories on which income estimates differ, which then essentially control for variation in inequality that is a function of fixed differences in definitions (e.g. Alderson and Nielson 1999; Lee 2005; Nielson and Alderson 1995). In other words, these dummy variables control for variation in Gini estimates by category under the assumption that those differences are invariant from country to country and year to year. ${ }^{4}$ More recent approaches to data comparability have instead attempted to pre-standardize the data by adjusting Gini coefficients in different categories for country-to-country and time invariant differences in income and reference unit (e.g. Babones and Alvarez-Rivadulla 2007;

\footnotetext{
${ }^{4}$ Another possible data set is the World Income Inequality Database (WIID), which has a total of 5,314 observations (UNU-WIDER 2008). However, this number drops to 508 observations on 71 countries if researches want to maximize comparability, and they are therefore forced to engage in some form of country and time invariant adjustments to increase the sample size (see Lee et al. 2007). Moreover, the SWIID data used here are a standardized version of the WIID data in that the standardization routine begins with WIID and standardizes them against the LIS Gini coefficients, and other variables.
} 
Galbraith and Kum 2005). Like the dummy variable approach discussed above, these standardization techniques address differences in measurement strategy with adjustments that are constant from country to country and year to year.

Yet, many note that it is likely that differences in Gini estimates owing to measurement strategy are not constant across countries or years (e.g. Bradley et al. 2003; Bergh 2005). For example, gross income and net income differ by the redistributive policy within a given nationstate at a given time, and such policies are anything but country and time invariant. Thus, "constant adjustments fail to capture the substantial variation across countries and over time in the differences between one income definition or reference unit and another" (Solt 2009: 234). In short, scholars of income inequality are faced with a trade off between comparability and sample size, and have attempted to overcome this with various methods that adjust for country and time invariant differences between the various definitions of the Gini coefficient. Thus, we obtain our Gini coefficients from the standardized world income inequality database (SWIID) (Solt 2009). Unlike previous approaches, the SWIID makes adjustments in which differences owing to definitions of income or reference unit are allowed to vary both across countries and over time. Our utilization of SWIID Gini coefficients express inequality in terms of net household disposable income, and thereby maximizes comparability for the broadest possible set of countries and years - up to 3,331 country-year observations on 153 countries from 1960 to 2008 (see Solt 2009).

\section{GDP per capita}

As noted above, economic development is the most common explanation for cross-national differences in income inequality. While there are many specific development processes that have been modeled in quantitative research, we control for GDP per capita and it squared term because this variable captures the general narrative associated with Kuznets and is the most common indicator of development (Heston, Summers and Ata 2006).

\section{World-System Position}

\section{Table 1. Coverage of Five World-System Position Measures}

\begin{tabular}{lll}
\hline Measure & Countries & Unique Time Periods \\
\hline \hline Babones (2009) & $102-181$ & $1960-2000$ \\
Clark and Beckfield (2009) & 144 & Average, 1980-1990 \\
Kentor et al. (2010) & 60 & Five year intervals, 1965-2005 \\
Mahutga and Smith (2011) & 94 & $1965,1980,2000$ \\
Snyder and Kick (1979)* & $127 *$ & Circa 1960 \\
\hline
\end{tabular}

Notes: *Update by Bollen 1983 and Bollen and Appold (1993)

Table 1 gives the sources for our measures of world-system position, the number of countries included in these measures and the time periods covered. 


\section{WITHIN-COUNTRY INEQUALITY AND THE WORLD-SYSTEM 290}

\section{METHODS}

These data consist of repeated (over time) observations of countries, and thereby call for statistical approaches that can deal with various types of auto-correlation. Time-series crosssection data are almost always serially correlated unless panels are severely unbalanced and unequally spaced. Moreover, the repeated observations are likely to produce spatial contemporaneous auto correlation within panels. Thus, we deal with both these processes by estimating and adjusting for a first-order auto regressive AR(1) process with Prais-Winston regression, and adjusting the standard errors with a sandwich estimator clustered on countries, or "Rogers" standard errors (Rogers 1993; Prais and Winston 1954). We also include T-1 yearly time dummies to sweep away unit-invariant time specific factors that might impact the estimates. ${ }^{5}$

Table 2. Descriptive Statistics and Sources for Variables Used in the Analysis

\begin{tabular}{|c|c|c|c|c|}
\hline & Mean & $\mathrm{SD}$ & $\%$ SSE between cases & Source \\
\hline 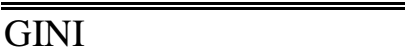 & 37.490 & 10.497 & 88.0 & Solt (2008) \\
\hline GDPpc (log) & 3.600 & 0.493 & 92.6 & Penn World Tables \\
\hline Snyder and Kick & 1.500 & 0.720 & 100.0 & $\begin{array}{l}\text { Snyder and Kick (1979), } \\
\text { Bollen (1983); Bollen and } \\
\text { Appold (1993) }\end{array}$ \\
\hline Clark and Beckfield & 1.760 & 0.894 & 100.0 & Clark and Beckfield (2009) \\
\hline Mahutga and Smith (cat) & 1.540 & 0.687 & 94.8 & Mahutga and Smith (2011) \\
\hline Mahutga and Smith (con) & -0.004 & 0.133 & 96.1 & Mahutga and Smith (2011) \\
\hline Babones & 1.807 & 0.824 & 90.6 & Babones (2008) \\
\hline Kentor & 0.000 & 3.361 & 98.5 & Kentor (2009) \\
\hline
\end{tabular}

While this approach effectively deals with biases owing to serial and spatially contemporaneous autocorrelation, it does not address the problem of unobserved unit (country) specific heterogeneity bias in the coefficient estimates. Unit specific heterogeneity occurs when unobserved time-invariant factors specific to a given unit (country) impact both right and left hand side variables, giving rise to (omitted variable) biased estimates of the coefficients. However, there is no straightforward way to deal with this bias because the vast majority of the variation in the variables on both sides of the equation lies between cases rather than within cases (over-time). Indeed, as Table 2 shows, the variation between cases ranges from 88 percent of the sum of squared errors (SSE) in the Gini coefficient to 100 percent for the Snyder and Kick's and Clark and Beckfield's world-system position measures. In such cases, the most conservative approach to unit-specific heterogeneity (the fixed effects model, or FEM) is either incapable of

\footnotetext{
${ }^{5}$ One reviewer wondered if the inclusion of T-1 time dummies had an effect on our results. In unreported analyses, the results for the WSP variables are stronger when either a linear time trend or no time adjustments are made. Since the main argument against time dummies (which are more conservative since they fully control for unmeasured case-invariant period effects) is about degrees of freedom (Green 2000) and our degrees of freedom are so great, we see no reason to employ less conservative approaches to the time dimension.
} 


\section{JOURNAL OF WORLD-SYSTEMS RESEARCH}

producing parameter estimates (when variables are time invariant) or provides extremely inefficient and therefore unreliable parameter estimates (when variables are slowly changing over time) (Plumper and Troeger 2007). The alternative approach (the random effects model, or REM) provides more efficient estimates than the FEM approach, but yields biased coefficient estimates if the unit-specific error term-the parameter that addresses unit-specific heterogeneity - is correlated with any of the right hand side variables, which is typically the case when the variation between cases is so much larger than that within (Halaby 2004; Plumper and Troeger 2007).

In other words, both of the standard approaches for dealing with unit-specific heterogeneity are inappropriate for these data because either (1) they are unable to identify coefficients on time-invariant (or nearly invariant) variables or (2) the assumption on which they are based is violated. ${ }^{6}$ Moreover, while addressing heterogeneity bias in panel data is most appropriate for causal inference, we are not currently trying to make causal inferences. Rather, we are trying to assess which among several measures of world-system position provide the strongest association with income inequality under the assumption that world-system position is a more or less time invariant (or nearly invariant) attribute that varies across countries. Thus, we rely on pooled OLS estimates that adjust for serial and spatial-contemporaneous auto correlation in order to identify the world-system indicator that provides the most empirically consistent relationship to income inequality.

One difficulty in comparing measures of world-system position is that they vary widely on both country and year coverage (see Tables 1 and 2). Thus, it is important to compare estimates of income inequality produced by these measures on common samples in order to minimize sampling effects. In order to draw these comparisons, we produce estimates of zonal income inequality (both descriptive statistics and model based estimates) across five sample restrictions. Sample (A) is unrestricted so that the countries/years included are entirely a function of the intersection between the countries included in a given measure of world-system position and the availability of Gini coefficients in SWIDD and GDP per capita. Sample restriction (B) is a common sample in which a country-year appears if and only if it is not missing any data on any measure of world-system position. Sample restriction (C) includes all country-years that are nonmissing for every world-system measure except Kentor et al. 2010, because their measure produced the fewest country observations. Sample restriction (D) includes all country-years that are non-missing for every world-system measure except Clark and Beckfield (2009), because their measure produced the fewest yearly observations. Sample restriction (E) includes all country-years that are non-missing for every world-system measure except Kentor et al. (2010) and Clark and Beckfield (2009), which thereby balances both data availability and comparability.

\footnotetext{
${ }^{6}$ One astute reviewer requested that we conduct Hausman tests to assess the validity of the REM assumption. It is impossible to compare the REM estimates with those of the FEM model—the basis of the Hausman test-on the key variable of interest in this study (world-system position) when it is time invariant because the latter cannot produce parameter estimates to compare, but the test did reject the null hypothesis of a zero correlation between world-system position and the unit specific random error term-or rather zero difference in the REM and FEM estimates of the coefficients - in cases where the covariate was nearly time invariant.
} 


\section{WITHIN-COUNTRY INEQUALITY AND THE WORLD-SYSTEM 292}

\section{RESULTS}

Table 3 reports several sets of descriptive statistics for the association between income inequality and world-system position across (1) sample restrictions and (2) different measurements of the world-system. These measurements of world-system position provide very different coverage, ranging from 2719 country-year observations on 141 countries for Babones down to 1552 country-year observations on 58 countries for Kentor. These descriptive statistics give a sense of which world-system position indicators bear the strongest association to income inequality at the bivariate level. The categorical measures can be evaluated on the extent to which they give the most theoretically consistent estimates of zonal mean income inequality, both in an absolute sense and relative to other zones, while the continuous measures can be evaluated in terms of which has the strongest negative association with income inequality. The differences reported in columns 57 of Table 3 are flagged for significance based on a one-way analysis of variance adjusted for multiple comparisons with a Bonferroni correction (Bonferroni 1936).

A natural place to begin the comparisons is with the estimates based on no sample restrictions as these comparisons maximize the case numbers for any given measure of worldsystem position, and thus provide the best sense of its power. The updated Snyder and Kick (SK) measure yields the lowest absolute estimate of income inequality for the core zone, while Clark and Beckfield's (CB) measure yields the highest estimate for the peripheral zone. Mahutga and Smith's (MS) measure yields the largest estimate of the relative difference in income inequality between the core and the periphery and the semiperiphery and periphery, while Babones' measure yields the largest estimate for the core/semiperiphery comparison. Turning to the two continuous measures, both Kentor and MS' estimates are significant and in the expected direction, though MS' is larger in size.

Panel B in Table 3 reports the descriptive statistics that result from a "least-common denominator" sample, which is decreased primarily by the small number of countries in Kentor and the shorter time-span in CB. The absolute estimates of zonal income inequality do not change much-SK's estimate of inequality in the core remains the lowest and doesn't change much in size, while CB's estimate of peripheral inequality remains the highest but increases in size by roughly 3 Gini points. The relative comparisons change more: Babones' measure produces the largest core/semiperiphery difference, while SK produces the largest core/periphery difference and MS produces the largest semiperiphery/periphery difference. Moreover, Kentor's continuous measure is now the larger of the two continuous measures. Panels C-D repeat the exercise by relaxing the sample restrictions. In panel $\mathrm{C}$, sample size is larger because the restrictions implied by Kentor's measure are excluded. In panel D, the restrictions implied by CB's measure are excluded, and in panel E, the restrictions implied by both Kentor and CB's measure are excluded. The only noticeable change in Panels C-E is that MS's continuous measure again shows the larger bivariate association with income inequality.

It is also natural to compare the four network measures with the two attribute measures. It turns out that both the smallest estimate of core inequality and the largest estimate of peripheral inequality are produced by network measures (SK and CB, respectively). The largest relative difference between the core/periphery accrues to a network measure (SK) and in fact all of the network estimates of the core/periphery difference are larger than the attribute measure (Babones). Likewise, the largest estimate of the difference between the semiperiphery/periphery also accrues to network measures, which are all larger than the attribute measure. 
Table 3. Bivariate Descriptive Statistics for Association Between World-System Position and Gini by Sample Restriction and World-System Indicator

\begin{tabular}{|c|c|c|c|c|c|c|c|c|c|c|}
\hline & \multicolumn{3}{|c|}{ Zonal Means } & \multirow{2}{*}{$r$} & \multicolumn{3}{|c|}{ Zonal Difference } & \multicolumn{3}{|c|}{ Coverage } \\
\hline & Core & Semiperiphery & Periphery & & C-SP & $\mathrm{C}-\mathrm{P}$ & SP-P & Countries & $\mathrm{N}$ & $\mathrm{T}$ \\
\hline \multicolumn{11}{|l|}{ (A) No Restrictions } \\
\hline Snyder and Kick & 28.25 (582) & $37.09(737)$ & $44.32(1210)$ & --- & $-8.84 * * *$ & $-16.07 * * *$ & $-7.23 * * *$ & 114 & 2529 & $1960+$ \\
\hline Clark and Beckfield & $32.19(955)$ & $43.77(324)$ & $45.98(713)$ & --- & $11.58 * * *$ & $-13.79 * * *$ & $-2.21 * * *$ & 114 & 1992 & $1980+$ \\
\hline Mahutga and Smith & $28.59(352)$ & $35.25(899)$ & $45.64(741)$ & --- & $-6.66 * * *$ & $-17.05 * * *$ & $10.39 * * *$ & 82 & 1992 & $1965+$ \\
\hline Mahutga and Smith Continuous & --- & --- & --- & $-.684 * * *$ & -- & -- & --- & 82 & 1992 & $1965+$ \\
\hline Babones & $30.47(879)$ & $42.26(807)$ & 43.09 (1033) & --- & $11.79 * * *$ & $-12.62 * * *$ & -0.83 & 141 & 2719 & $1960+$ \\
\hline Kentor & --- & --- & --- & $-.597 * * *$ & --- & --- & --- & 58 & 1552 & $1965+$ \\
\hline (B) Common Sample & & & & & & & & 51 & 1065 & $1980+$ \\
\hline Snyder and Kick & 28.17 (339) & $35.93(348)$ & $44.64(378)$ & --- & $\begin{array}{c}-7.76^{* * *} \\
-\end{array}$ & $-16.47 * * *$ & $-8.71 * * *$ & --- & --- & \\
\hline Clark and Beckfield & $32.46(732)$ & $43.61(211)$ & $48.87(122)$ & --- & $11.15^{* * *}$ & $-16.41 * * *$ & $-5.26 * * *$ & --- & --- & \\
\hline Mahutga and Smith & $28.61(207)$ & $35.31(563)$ & $44.48(295)$ & --- & $-6.70 * * *$ & $-15.87 * * *$ & $-9.16 * * *$ & --- & --- & \\
\hline Mahutga and Smith Continuous & --- & --- & --- & $-.632 * * *$ & -- & --- & --- & --- & --- & \\
\hline Babones & $28.82(479)$ & $44.08(304)$ & $41.56(282)$ & --- & $15.26^{* * *}$ & $-12.74 * * *$ & $2.52 * * *$ & --- & --- & \\
\hline Kentor & --- & --- & --- & $-.640 * * *$ & --- & --- & --- & --- & --- & \\
\hline \multicolumn{10}{|l|}{ (C) Common Sample (Except } & $1980+$ \\
\hline Snyder and Kick & $28.08(362)$ & $36.64(442)$ & $45.70(644)$ & --- & $\begin{array}{c}-8.56^{* * *} \\
-\end{array}$ & $-17.62^{* * *}$ & $-9.06 * * *$ & --- & --- & \\
\hline Clark and Beckfield & $32.69(822)$ & $43.77(262)$ & $47.95(364)$ & --- & $11.08 * * *$ & $-15.26^{* * *}$ & $-4.18 * * *$ & --- & --- & \\
\hline Mahutga and Smith & $28.43(230)$ & $35.41(630)$ & $45.51(588)$ & --- & $-7.27 * * *$ & $-17.09 * * *$ & $-9.80 * * *$ & --- & --- & \\
\hline Mahutga and Smith Continuous & --- & --- & --- & $-.687 * * *$ & --- & --- & --- & --- & --- & \\
\hline Babones & $29.24(543)$ & $44.12(456)$ & $44.10(449)$ & --- & $14.88^{* * *}$ & $-14.86^{* * * *}$ & 0.02 & -- & -- & \\
\hline Kentor (same as B) & --- & --- & --- & --- & --- & --- & --- & --- & --- & \\
\hline
\end{tabular}

Notes: Numbers in parentheses are number of country, year observations per zone. Bold figures indicate most favorable world-system estimate within sample restriction. Interzonal comparisons made with a one-way analysis of variance with a Bonferroni adjustment for multiple comparisons. Continuous associations are correlation coefficients. ${ }^{* * *} p<.001$ 
Table 3. Bivariate Descriptive Statistics for Association Between World-System Position and Gini by Sample Restriction and World-System Indicator (Continued)

\begin{tabular}{|c|c|c|c|c|c|c|c|c|c|c|}
\hline & \multicolumn{3}{|c|}{ Zonal Means } & \multicolumn{4}{|c|}{ Zonal Difference } & \multicolumn{3}{|c|}{ Coverage } \\
\hline & Core & Semiperiphery & Periphery & $r$ & $\mathrm{C}-\mathrm{SP}$ & C-P & SP-P & Countries & $\mathrm{N}$ & $\mathrm{T}$ \\
\hline $\begin{array}{l}\text { (D) Common Sample (Except } \\
\text { Clark \& Beckfield) }\end{array}$ & & & & & & & & 51 & 1360 & $1965+$ \\
\hline Snyder and Kick & $28.27(472)$ & $35.49(426)$ & $44.67(462)$ & --- & $-7.22 * * *$ & $-16.39 * * *$ & $-9.18^{* * *}$ & --- & --- & \\
\hline Clark and Beckfield (same as B) & --- & --- & --- & --- & --- & --- & --- & --- & --- & \\
\hline Mahutga and Smith & $28.67(307)$ & $35.32(723)$ & $44.76(330)$ & --- & $-6.65 * * *$ & $-16.06 * * *$ & $-9.41 * * *$ & --- & --- & \\
\hline Mahutga and Smith Continuous & --- & -- & --- & $-.625 * * *$ & --- & --- & -- & --- & --- & \\
\hline Babones & $28.91(648)$ & $43.61(367)$ & $41.63(345)$ & & $-14.70^{* * *}$ & $-12.72 * * *$ & $1.98 * * *$ & --- & --- & \\
\hline Kentor & --- & --- & --- & $-.621 * * *$ & --- & --- & --- & --- & --- & \\
\hline $\begin{array}{l}\text { (E) Common Sample (Except } \\
\text { Kentor and Clark \& Beckfield) }\end{array}$ & & & & & & & & 79 & 1876 & $1965+$ \\
\hline Snyder and Kick & $28.20(500)$ & $36.26(566)$ & $45.62(810)$ & --- & $-8.06^{* * *}$ & $-17.42 * * *$ & $-9.36^{* * *}$ & --- & --- & \\
\hline Clark and Beckfield (same as C) & --- & --- & --- & --- & --- & --- & --- & --- & --- & \\
\hline Mahutga and Smith & $28.52(335)$ & $35.61(842)$ & $45.83(699)$ & --- & $-7.09 * * *$ & $-17.31 * * *$ & $-10.22^{* * *}$ & --- & --- & \\
\hline Mahutga and Smith Continuous & --- & -- & --- & $-.696 * * *$ & -- & --- & --- & --- & --- & \\
\hline Babones & $29.78(767)$ & $44.12(553)$ & $43.77(556)$ & --- & $-14.34^{* * *}$ & $-13.99 * * *$ & 0.34 & --- & --- & \\
\hline Kentor (same as D) & --- & --- & --- & --- & --- & --- & --- & --- & --- & \\
\hline
\end{tabular}

Notes: Numbers in parentheses are number of country, year observations per zone. Bold figures indicate most favorable world-system estimate within sample restriction. Interzonal comparisons made with a one-way analysis of variance with a Bonferroni adjustment for multiple comparisons. Continuous associations are correlation coefficients. ${ }^{* * *} p<.001$

However, the Babones measure produces the largest core/semiperiphery difference across all sample restrictions, and this in turn reflects the fact that the association between Babones and inequality is curvilinear in four out of five sample restrictions. While this might be unsurprising since the Babones measure is derived from per capita output, it is noteworthy that all of the zonal differences in column 5-7 are statistically significant except for two of the four Babones semiperiphery-periphery differences that imply a curvilinear association. Turning to the continuous measures, MS produces the strongest negative bivariate association in all sample restrictions except panel B, where Kentor's sample is the least common denominator.

Table 4 reports partial results of 52 regression models in which income inequality is regressed on T-1 yearly dummy variables, world-system position and a development quadratic after estimating and adjusting for a first order-auto regressive process. We estimated 26 models with the core as the excluded category, and re-estimated them with the periphery as the excluded category, allowing us to assess the significance of each relevant zonal comparison. The second through fourth columns in Table 4 report the estimated mean difference between the core and the 


\section{JOURNAL OF WORLD-SYSTEMS RESEARCH}

two non-core zones as well as the semiperiphery and periphery, respectively, and flag significant differences conventionally. The fifth column reports the estimated unstandardized coefficient on continuous world-system position with conventional significance flags. Columns six and seven indicate if either the linear or quadratic term for development (GDP per capita) is significant net of world-system position. Finally, column eight reports the estimate of the AR(1) term and column nine reports the $\mathrm{R}^{2}$ for each model. ${ }^{7}$

The first-order auto-regressive signal is exceptionally strong in these data-the estimated AR(1) term ranges from a low of .975 to a high of .986 . The F statistic in Table 5 tests the null hypothesis that the AR(1) term is zero, which is rejected in all replications. Moreover, worldsystem and development dynamics (plus time dummies) explain an exceptionally high amount of the variation in income inequality, with $\mathrm{R}^{2}$ values ranging from .702 to $.803 .^{8}$

The rows in Table 4 are sorted first on the measures of world-system position and then on sample restrictions in order to make measure-to-measure comparisons easier to decipher. Of interest is whether or not (1) the positional comparisons/continuous associations are statistically significant and (2) whether or not the development term is significant net of world-system position. The most robust measure by this criterion is SK, in which the mean differences between each zone are significant, while the development quadratic is not significant in any replication. Following SK, the continuous version of MS is significant in each model, but the development quadratic is at least marginally significant in two of the five models. CB's measure shows a significant difference between the core and non-core zones in all three unique models estimated, but a significant difference between the semiperiphery and periphery only in sample restriction B. Moreover, the development quadratic is at least marginally significant in two of the three models.

\footnotetext{
${ }^{7}$ The reader should note that the $\mathrm{AR}(1)$ term, $\mathrm{R}^{2}$ value and estimates of the quadratic term are naturally the same regardless of which world-system zone is the excluded category, and therefore only need to be reported once.

${ }^{8}$ The $\mathrm{R}^{2}$ values range from .669 to .768 in models with no sample restrictions that do not include time dummies. .
} 
Table 4. Summary of 52 Regressions of Gini on World-System Position and Development Quadratic

\begin{tabular}{|c|c|c|c|c|c|c|c|c|c|}
\hline & & Categorical & & Cont. & & Ppc & & & \\
\hline & $\begin{array}{l}\text { Periphery- } \\
\text { Core }\end{array}$ & $\begin{array}{l}\text { SemiP- } \\
\text { Core } \\
\end{array}$ & $\begin{array}{c}\text { Periphery } \\
\text {-SemiP } \\
\end{array}$ & $\mathrm{b}$ & Linear & $\begin{array}{c}\text { Quadratic } \\
\text { Term } \\
\end{array}$ & $\rho$ & $F$ & $\mathrm{R}^{2}$ \\
\hline \multicolumn{10}{|l|}{$\begin{array}{l}\text { Snyder and Kick } \\
\text { (A) Unrestricted: } \mathrm{C}=107 ; \mathrm{N}=\end{array}$} \\
\hline (B) Common & $15.294 * * *$ & $7.066 * *$ & $8.228 * * *$ & & --- & --- & .984 & $292.7 * * *$ & .708 \\
\hline (C) Common no Kentor & $14.446^{* * * *}$ & $7.056^{* * *}$ & $7.390 * * *$ & & --- & --- & .977 & $186.5^{* * * *}$ & .719 \\
\hline $\begin{array}{l}\text { (D) Common no C \& B } \\
\text { (E) Common no C \& B or }\end{array}$ & $17.977 * * *$ & $5.856^{*}$ & $12.121 * * *$ & & --- & --- & .986 & $25.4 * * *$ & .757 \\
\hline Kentor & $17.370 * * *$ & $6.623 * *$ & $1.747 * * *$ & & --- & --- & .982 & $73 * * *$ & .769 \\
\hline $\begin{array}{l}\text { Clark and Beckfield } \\
\text { (A) Unrestricted: } \mathrm{C}=108 ; \mathrm{N}= \\
\qquad 1870\end{array}$ & $9.787 * * *$ & $9.283 * * *$ & .504 & & --- & $\dagger$ & .974 & 392.97 *** & .702 \\
\hline (B) Common & $13.884 * * *$ & $8.560 * * *$ & $5.324 *$ & & $\dagger$ & $*$ & .98 & $279.8 * * *$ & .74 \\
\hline (C) Common no Kentor & $1.461 * * *$ & $7.699 * * *$ & 2.762 & & --- & --- & .977 & $193.1 * * *$ & .716 \\
\hline $\begin{array}{r}\text { (D) Common no C \& B } \\
\text { (E) Common no C \& B or } \\
\text { Kentor }\end{array}$ & \multicolumn{9}{|c|}{ Same as (B) } \\
\hline $\begin{array}{l}\text { Mahutga and Smith } \\
\text { (A) Unrestricted: C =79; N = } \\
1903\end{array}$ & $4.469 * *$ & $2.641^{\dagger}$ & $1.828^{*}$ & & --- & --- & .978 & $7.45 * * * *$ & .778 \\
\hline (B) Common & 2.976 & $1.198^{\dagger}$ & 1.778 & & * & $*$ & .981 & $292.92 * * *$ & .722 \\
\hline (C) Common no Kentor & $3.156^{* *}$ & $1.581^{\dagger}$ & $1.575^{\dagger}$ & & --- & --- & .976 & $186.4 * * *$ & .711 \\
\hline $\begin{array}{l}\text { (D) Common no C \& B } \\
\text { (E) Common no C \& B or }\end{array}$ & $3.506^{* *}$ & $1.685^{\dagger}$ & $1.820^{\dagger}$ & & --- & $\dagger$ & .978 & $23.6^{* * *}$ & .797 \\
\hline Kentor & $4.183 * *$ & $2.416^{\dagger}$ & $1.767 *$ & & --- & --- & .979 & $69.4 * * *$ & .769 \\
\hline
\end{tabular}

Notes: AR(1) term denoted by $\rho$. F statistic based on Wooldridge test for serial correlation in panel data, where the null hypothesis is zero autocorrelation (Wooldridge 2002). Significance of coefficients based on standard errors adjusted for spatial contemporaneous autocorrelation with the clustered sandwich estimator (Rogers 1993). Models also include T-1 yearly dummy variables. Sample sizes: (B) $C=51, N=1065$; $(C) C=76, N=1448$; $(D) C=51, N=1358$; $C$ $=79, N=1874 ; \dagger p<.10 ; * p<.05 ; * * p<.01 ; * * * p<.001$ 
Table 4. Summary of 52 Regressions of Gini on World-System Position and Development Quadratic Continued

\begin{tabular}{|c|c|c|c|c|c|c|c|c|c|}
\hline & \multicolumn{3}{|c|}{ Categorical } & \multirow{2}{*}{$\begin{array}{l}\text { Cont. } \\
\quad \mathrm{b} \\
\end{array}$} & \multicolumn{2}{|c|}{ GDPpc } & \multirow[b]{2}{*}{$\rho$} & \multirow[b]{2}{*}{$F$} & \multirow[b]{2}{*}{$\mathrm{R}^{2}$} \\
\hline & $\begin{array}{l}\text { Periphery- } \\
\text { Core }\end{array}$ & $\begin{array}{l}\text { SemiP- } \\
\text { Core }\end{array}$ & $\begin{array}{c}\text { Periphery } \\
\text {-SemiP } \\
\end{array}$ & & Linear & $\begin{array}{c}\text { Quadratic } \\
\text { Term } \\
\end{array}$ & & & \\
\hline \multicolumn{10}{|l|}{ Mahutga and Smith Continuous } \\
\hline (A) Unrestricted: $C=79 ; \mathrm{N}=1903$ & & & & $-17.663 * * *$ & --- & --- & .979 & $7.54 * * *$ & .774 \\
\hline (B) Common & & & & $-15.291 * * *$ & $*$ & $*$ & .982 & $298.9^{* * *}$ & .711 \\
\hline (C) Common no Kentor & & & & $-11.339 *$ & --- & --- & .977 & $187.1 * * *$ & .703 \\
\hline (D) Common no C \& B & & & & $-16.036^{* * *}$ & $\dagger$ & $*$ & .978 & $23.6^{* * *}$ & .795 \\
\hline (E) Common no C \& B or Kentor & & & & $-16.991 * * *$ & --- & --- & .981 & $69.5 * * *$ & .764 \\
\hline \multicolumn{10}{|l|}{ Babones } \\
\hline (A) Unrestricted: $\mathrm{C}=138 ; \mathrm{N}=2672$ & $1.291 * *$ & $1.236^{* *}$ & .055 & & --- & $\dagger$ & .978 & $173.6 * * *$ & .768 \\
\hline (B) Common & $.926^{*}$ & $.964 * *$ & -.038 & & $*$ & $*$ & .98 & $334.9^{* * *}$ & .729 \\
\hline (C) Common no Kentor & $.815^{* *}$ & $.885 * * *$ & -.07 & & --- & --- & .975 & $192.8 * * *$ & .715 \\
\hline (D) Common no C \& B & $1.735 * *$ & $1.617 * *$ & .118 & & $\dagger$ & $*$ & .976 & $26^{* * * *}$ & .803 \\
\hline (E) Common no C \& B or Kentor & $1.695 * * *$ & $1.586^{* * * *}$ & .103 & & --- & --- & .979 & $75.3^{* * *}$ & .769 \\
\hline \multicolumn{10}{|l|}{ Kentor } \\
\hline (A) Unrestricted: $\mathrm{C}=58 ; \mathrm{N}=1501$ & & & & -.046 & $*$ & $* *$ & .978 & $49.6^{* * * *}$ & .777 \\
\hline (B) Common & & & & $-.600 *$ & $*$ & $* *$ & .98 & $293.3 * * *$ & .725 \\
\hline (C) Common no Kentor & \multicolumn{9}{|c|}{ Same as (B) } \\
\hline (D) Common no C \& B & & & & $-.637 *$ & $\dagger$ & $*$ & .997 & $23.6^{* * * *}$ & .798 \\
\hline (E) Common no C \& B or Kentor & \multicolumn{9}{|c|}{ Same as (D) } \\
\hline
\end{tabular}

Notes: AR(1) term denoted by $\rho$. F statistic based on Wooldridge test for serial correlation in panel data, where the null hypothesis is zero autocorrelation (Wooldridge 2002). Significance of coefficients based on standard errors adjusted for spatial contemporaneous autocorrelation with the clustered sandwich estimator (Rogers 1993). Models also include T-1 yearly dummy variables. Sample sizes: (B) $C=51, N=1065$; $(C) C=76, N=1448$; $(D) C=51, N=1358$; $C$ $=79, N=1874 ; \dagger p<.10 ; * p<.05 ; * * p<.01 ; * * * p<.001$ 


\section{WITHIN-COUNTRY INEQUALITY AND THE WORLD-SYSTEM 298}

MS's categorical measure shows at least marginally significant differences between each zone in four of the five models, while the development quadratic is significant in one of the five models, and marginally significant in another. The Babones measure shows a significant difference between the core and both non-core zones in each model, but the semiperiphery-periphery comparison is not significant in any model and the development quadratic is at least marginally significant in three of the five models. Finally, Kentor's measure produces a significant effect in two of the three models, and the development quadratic is significant in all three models. ${ }^{9}$

Comparing the network and attribute measures as a group suggests that the network measures are somewhat better predictors of inequality than are attribute measures. There are 39 possible significant zonal differences for the models with the categorical world-system position measures. Of these 39,35 or $89.7 \%$ are at least marginally significant. There are only 15 possible significant zonal differences for the attribute measures, of which 10 or $66.67 \%$ are significant. Moreover, five of the five possible continuous network measures are significant while only two out of three possible continuous attribute measures are significant, and the development quadratic remains significant in only two of five continuous network models but all of the continuous attribute models. Overall, network based measures of world-system position explain away the development quadratic in two thirds (12 of 18) of the replications, while the attribute measures do so in only one quarter ( 2 of 8$)$ of the replications. While this analysis can in no way resolve the debate over the superiority of network based measures of the world-system over attribute based ones, it does lend some empirical support to the network side. That being said, even the attribute measures of world-system position are more often significant predictors of income inequality than not. ${ }^{10}$ Future work could unpack these comparisons by identifying if there are systematic differences in the categorization of particular countries across the relational and attribute based approaches, and the extent to which such disagreements speak to the theoretical validity of one approach over the other.

The somewhat surprising outcome of the analyses in Tables 3 and 4 is that the updated Snyder and Kick measure seems to be the superior measure of world-system position as an estimate of income inequality. This is surprising because previous research has found this measure to be fragile (e.g. Alderson and Nielsen 1999; Lee 2005; Lee et al. 2007; Weede and Kummer 1985; c.f. Nolan 1983; Bollen 1987). Yet, previous work differs from these analyses in a number of ways. One major difference is the choice of Gini coefficients as discussed above, which not only made assumptions about the invariance of definitional Gini differences across

\footnotetext{
${ }^{9}$ One particularly astute reviewer pointed out that the $\mathrm{CB}$ measure does provide the largest measure of fit $\left(\mathrm{R}^{2}\right)$ in sample restriction $\mathrm{B}$ (the common panels), and that by this criterion is stronger than Snyder and Kick even though CB's SP/P comparison is only significant at the .05 level. Thus, we checked the BIC statistic for these two models and found the SK model yields a 28 point reduction in BIC vis-à-vis the CB model. This result, coupled with the highly significant zonal differences in SK that are invariant to sample restrictions and the smaller time period covered by CB leads us to the conclusion that SK has an edge over all measures of WSP, even though the CB measure is also a strong predictor of inequality.

${ }^{10}$ One reviewer was curious about whether or not there is evidence for a curvilinear relationship between income inequality and world-system position. We found such evidence for the Babones measure, which is unsurprising given the pattern of results in Tables 3 and 4 and that it is based on per capita output. Beyond that, there was only very weak evidence for a curvilinear association in both the Clark (2010) measure and MS according to BIC statistics and the significance of the squared term, and even this weak evidence was fragile to sample selection.
} 
countries and time periods, but also yields much smaller data sets. A second major difference is that previous tests of the world-system position-inequality link used two primary methodologies - cross-sectional ordinary least squares regression (e.g. Nielsen 1994; Nolan 1983) and panel models with random effects (Alderson and Nielsen 1999; Lee 2005; Lee et al. 2007). The former exacerbate problems of small sample size, while the latter did not include adjustments for serial correlation. ${ }^{11}$ Finally, a third major difference is that the cited panel studies also controlled for what has become a standard baseline inequality model-the internal development model - that includes the percent of the labor force in agriculture, sector dualism, the natural rate of population increase and secondary education enrollment (e.g. Alderson and Nielsen 1999; 2002; Lee 2005; Lee et al. 2007; Nielsen 1994).

Thus, we present one final series of models to see if the updated Snyder and Kick measure is robust to the inclusion of random effects and the internal development model. Like previous work, we control for the percent of the labor force in agriculture (FAOUN 2006), sector dualism (the percent of the labor force in agriculture minus the share of GDP in agriculture), the percent of the relevant school aged population enrolled in secondary education and the natural rate of population increase (birth rate minus death rate). These data come from the World Bank (2003) unless otherwise noted. We regress the Gini coefficient on indicators for semiperiphery and periphery from the updated Snyder and Kick (1979) measure, along with GDP per capita and the internal development model. In order to compare with previous work, we estimated GLS random effects models. However, we also estimate and adjust for a first-order auto regressive process because of the exceptionally high AR(1) signal in these data and also include T-1 yearly dummy variables.

Table 5 reports estimates of these models. Much like the estimates reported in Table 4, the AR(1) signal is exceptionally high in these models, ranging from .883 to .889 . Model 1 shows that the Snyder and Kick measure is robust to the inclusion of the random effects. Model 2 shows that it is robust to inclusion of the development quadratic along with the random effects. Model 3 shows that it is robust to the internal development model and random effects, but also that the size of the zonal differences attenuate when the core development model is included, which could suggest that part of the explanation for difference in income inequality between world-system zones is differences in levels of economic development. On the other hand, model 4 shows that all the coefficients on the development covariates except for sector dualism are either in the expected direction (the GDP pc quadratic) or larger in size when world-system position is not controlled, suggesting in turn that world-system dynamics explain some of the link

\footnotetext{
${ }^{11}$ Two reviewers highlighted this important difference between our work and previous work. One correctly pointed out that it is likely that earlier panels models would have had less serial correlation to adjust for because there were fewer over time observations, while the other suggested that our results may not provide "apples-to-apples" comparisons with earlier work because our models approach first difference models as $\rho$ approaches 1. While we believe that failing to account for the significant AR(1) process in these data would decrease confidence in our results and provide less conservative estimates of the association between world-system position and income inequality, we nevertheless estimated both OLS and REM models without an AR(1) correction for the unrestricted and common sample panels (A and B) at the reviewer's request. These results were substantively identical to those presented in terms of the relative comparison of the association between world-system position and inequality across measures of worldsystem position. In most cases the association between WSP and inequality was larger than that reported here.
} 
between development and income inequality. Finally, model 5 shows that world-system position is robust to the random effects as well as all of the conventional development covariates. Compared to model 1, the inter-zonal inequality differences remain attenuated but are slightly larger than those in model 3. Compared to model 4, all the coefficients on the development model except for dualism are either smaller or opposite the expected direction. Consistent with the theoretical discussion outlined above, there are clearly either indirect effects of world-system position that work through development and/or a significant degree of redundancy between these models. $^{12}$ In tandem, these reinforce the suggestion that the association between world-system position and development dynamics is an important topic for future research.

Table 5. AR(1) Corrected Random Effects Regression of Income Inequality on WorldSystem Position and Economic Development

\begin{tabular}{|c|c|c|c|c|c|}
\hline & 1 & 2 & 3 & 4 & 5 \\
\hline \multicolumn{6}{|l|}{ World-System Position } \\
\hline Semiperiphery & $\begin{array}{c}8.965^{* * *} \\
(2.334)\end{array}$ & $\begin{array}{c}9.302 * * * \\
(2.215)\end{array}$ & $\begin{array}{c}7.118^{* * * *} \\
(1.920)\end{array}$ & --- & $\begin{array}{c}7.572 * * * \\
(1.961)\end{array}$ \\
\hline Periphery & $\begin{array}{c}16.952 * * * \\
(2.039)\end{array}$ & $\begin{array}{c}17.412 * * * \\
(2.215)\end{array}$ & $\begin{array}{c}13.116^{* * * *} \\
(1.944)\end{array}$ & --- & $\begin{array}{c}13.741 * * * \\
(2.025)\end{array}$ \\
\hline \multicolumn{6}{|l|}{ Economic Development } \\
\hline GDP pc & --- & $\begin{array}{l}-2.707 \\
(7.040)\end{array}$ & --- & $\begin{array}{l}11.021 \\
(7.091)\end{array}$ & $\begin{array}{c}1.305 \\
(7.203)\end{array}$ \\
\hline GDP pc sq & --- & $\begin{array}{c}.427 \\
(.989)\end{array}$ & --- & $\begin{array}{l}-1.538 \\
(.976)\end{array}$ & $\begin{array}{c}.043 \\
(1.000)\end{array}$ \\
\hline$\%$ Laborforce in Agriculture & --- & --- & $\begin{array}{c}.027 \\
(.023)\end{array}$ & $\begin{array}{c}.096 * * * \\
(.025)\end{array}$ & $\begin{array}{l}.043 \dagger \\
(.026)\end{array}$ \\
\hline Sector Dualism & --- & --- & $\begin{array}{l}.034 * \\
(.015)\end{array}$ & $\begin{array}{l}.029 \dagger \\
(.015)\end{array}$ & $\begin{array}{l}.032 * \\
(.015)\end{array}$ \\
\hline Secondary Education & --- & --- & $\begin{array}{l}-.007 \\
(.005)\end{array}$ & $\begin{array}{l}-.009 \dagger \\
(.005)\end{array}$ & $\begin{array}{l}-.007 \\
(.005)\end{array}$ \\
\hline Natural Rate of Population Increase & --- & --- & $\begin{array}{l}.059 \dagger \\
(.036)\end{array}$ & $\begin{array}{l}.109^{* * *} \\
(.035)\end{array}$ & $\begin{array}{l}.065 \dagger \\
(.036)\end{array}$ \\
\hline Constant & $\begin{array}{c}30.962 * * * \\
(1.872)\end{array}$ & $\begin{array}{c}34.851 * * \\
(12.634)\end{array}$ & $\begin{array}{c}30.962 * * * \\
(1.872)\end{array}$ & $\begin{array}{c}15.301 \\
(13.313)\end{array}$ & $\begin{array}{l}22.967 \dagger \\
(13.231)\end{array}$ \\
\hline$\rho$ & .889 & .887 & .886 & .883 & .883 \\
\hline $\mathrm{R}^{2}$ & .408 & .403 & .466 & .405 & .465 \\
\hline
\end{tabular}

Notes: Coefficients are unstandardized AR(1) corrected random effects regression coefficients. T-1 yearly dummy variables were included but not reported. Numbers in parentheses are standard errors. AR(1) term denoted by $\rho .+p<.10 ; * p<.05 ; * * p<.01 ; * * * p<.001$. Estimates include 2216 observations on 103 countries in all models.

\footnotetext{
${ }^{12}$ Uncentered variance inflation factors are above 10 for each of the development covariates in model 5.
} 


\section{CONCLUSION}

The world-systems perspective suggests that the distribution of income within countries is at least in part a function of their position in the world-system. World-system dynamics should matter for income inequality, at least in theory. Yet, the quantitative macro-comparative literature on income inequality suggests only weak support for the world-system position—inequality link. One potential explanation for this is that direct tests of this link uniformly rely upon the updated version of the classic measure of Snyder and Kick (1979) as the basis for assigning countries to world-system positions, but there now exist a number of world-system position measures that differ by their use of either country attributes (Babones 2009; Kentor et al. 2010) or international relationships (Clark and Beckfield 2009; Mahutga and Smith 2011; Snyder and Kick 1979). Thus, our immediate goal in this paper was to identify the most robust measure of world-system position as an initial step toward reinvigorating empirical investigations of the role of worldsystem dynamics as determinants of income inequality. Secondarily, we also brought evidence to bear on an internal debate among world-systems analysts regarding the appropriateness of relational measures of world-system dynamics relative to attribute based ones.

Our results suggest that the majority of world-system measures bore relationships with income inequality that were theoretically consistent with the world-system perspective, but varied in terms of the strength of the association. While the relational measures seemed generally stronger than attribute based ones, the strongest measure of world-system position was the updated version of Snyder and Kick (1979), in which mean differences between each zone of the world-system were significantly different net of economic development, T-1 dummy variables, adjustments for autocorrelation across five different sample restrictions, as well as additional development covariates and random effects. While the coefficients reported in Table 5 show that Snyder and Kick remained significant net of the core developmental model, they also leave open a number of substantive questions regarding the prime mover cross-national variation in income inequality. ${ }^{13}$

Two primary means by which the utility of general theory can be evaluated is the extent to which it leads to explicit hypotheses and integrates existing findings from empirical work (Mahoney 2004: 465-468). Arguably, our review of the literature on cross-national variation in income inequality suggests two general theories. One prioritizes economic development, and contends that individual nation-states are the appropriate unit of analysis, and further that a more or less cross-nationally homogenous developmental path is the primary mover of variation in income inequality. Contrarily, world-system analysts contend that the whole world-system is the appropriate unit of analysis, that levels of income inequality in one zone are not independent of those in others and that historically evolving forms of inter-state capitalist competition constitute the mechanisms that govern relative levels of inequality across world-system zones.

\footnotetext{
${ }^{13}$ One reviewer pointed to the merits of including the full development controls for all of the world-system position covariates to see if our conclusions remain the same. Thus, we ran the full model in Table 5 for all of the world-system position measures in both the unrestricted samples and the common panel samples (panels A and B in Table 4). The results were substantively identical in terms of the comparative strength of the world-system position effects and in that the size of the zonal differences attenuated when the development controls were included across all world-system position measures.
} 


\section{WITHIN-COUNTRY INEQUALITY AND THE WORLD-SYSTEM 302}

Thus, one way to juxtapose world-systemic and developmental perspectives on income inequality is to regard them as explanations for levels of income inequality that operate at different levels of analysis. To the extent that theories of development can identify developmental processes that bear directly on income inequality in any particular country, for example, world-system analysts can identify macro-level processes that lead to different levels of development across world-system zones.

In fact, our discussion above suggests two particular types of hypotheses: those in which world-system position has an indirect effect on inequality that works through known developmental processes and those in which world-system position has a direct effect on income inequality through mechanisms that are more or less unobservable because they change over time or belie cross-nationally comparative data. Thus, a potentially fruitful next step involves untangling the direct and indirect effects of world-system position. The amount of variation in income inequality attributable to unobservable world-system mechanisms can be identified in statistical models that incorporate a robust set of control variables that have been shown to correlate with income inequality (e.g. Alderson and Nielsen 1999). Above and beyond the internal development model highlighted above, such models should include the role of institutions and particularly levels of democracy and the ideological orientation of nation states. ${ }^{14}$ Moreover, "dependency" mechanisms - including covariates such as foreign capital penetration and concentration, commodity and trade partner concentration, etc.- -should be included to parcel out world-systemic processes owing to observable dependency relations from those owing to unobservables (eg. Lee et al. 2007). ${ }^{15}$ In such a model, variation in income inequality owing to world-systemic unobservables should be that accruing to coefficients on world-system position net of a robust set of control variables.

For those mechanisms in which the causal sequence is world-system position $\rightarrow$ development $\rightarrow$ inequality, scholars must test for the effect of world-system position on the development processes highlighted in the current literature. Such an analysis could involve the use of structural equation modeling (SEM) approaches that can deal with complex departures from strict variable exogeneity. While the use of SEMs in the context of panel data is uncommon, the methodological literature is now developing ways to deal with time-invariant unit effects with SEMs (Bollen and Brand 2010). An alternative identification strategy would involve more carefully designed "hybrid" panel models that can deal with the problem of time-invariant unit-specific heterogeneity in order to handle time invariant or rarely changing variables, as well as incorporate simultaneous equations (see Alison 2005; Plumper and Troeger 2007). In either case, the indirect effects of world-system position can be identified with coefficients from worldsystem position to developmental or institutional covariates while holding constant the direct

14 Indeed, the precise association between income inequality and democracy has been explored (and contested) to such an extent that it probably belongs in any serious baseline model (Hewitt 1977; Muller 1988; c.f. Lee 2005; Simpson 1990). Moreover, former socialist societies that were not particularly democratic still experienced comparatively low levels of income inequality precisely because of the ideological orientation of the communist state, as have a number of Western European states (Alderson and Nielsen 1999; Bandelj and Mahutga 2010; Rueda and Pontusson 2000).

${ }^{15}$ Moreover, because one of the central claims of world-system scholars is that the evolution of the worldsystem produces varying manifestations of competition and exploitation across time and space, care should be taken to assess whether or not dependency effects vary over time and/or across zones of the worldsystem. 
effects of world-system position, development, dependency and institutional factors (see Kollmeyer 2009 for an application of simultaneous equations in a recent model of deindustrialization to estimate the direct and indirect effects of globalization). ${ }^{16}$ Ultimately, then, the total effect of world-system position would be the sum of the direct and indirect effects in models with a robust set of control variables that can identify both direct and indirect worldsystem effects.

\section{ACKNOWLEDGEMENTS}

The authors would like to thank the editors of JWSR and four anonymous reviewers for some particularly thorough and ultimately very helpful comments on earlier iterations of this article. All remaining logical, empirical and technical errors are the sole responsibility of the authors. Direct all comments and correspondence to Matthew C Mahutga, Department of Sociology, University of California at Riverside, matthew.mahutga@ucr.edu.

\section{REFERENCES}

Alderson, Arthur and Francois Nielsen. 1999. "Income Inequality, Development, and Dependence: A Reconsideration.” American Sociological Review 64: 606-31. . 2002. "Globalization and the Great U-Turn: Income Inequality Trends in 16 OECD Countries." American Journal of Sociology 107: 1244-99.

Alison, Paul D. 2005. Fixed Effects Regression Methods for Longitudinal Data Using SAS. Cary, NC: SAS Institute Inc.

Arrighi, Giovanni, Beverly J. Silver and Benjamin D. Brewer. 2003. "Industrial Convergence, Globalization, and the Persistence of the North-South Divide." Studies in Comparative International Development 38: 3-31.

Babaones, Salvatore. 2009. The International Structure of Income: Its Implications for Economic Growth. Germany: VDM.

Babones, Salvatore J. and Maria Jose Alvarez-Rivadulla. 2007. "Standardized Income Inequality Data for Use in Cross-National Research." Sociological Inquiry 77:3-22.

Bandelj, Nina and Matthew C. Mahutga. 2010. "How Socio-Economic Change Shapes Income Inequality in Central and Eastern Europe." Social Forces 88(5): 2133-61.

Beer, Linda and Terry Boswell. 2002. "The Resilience of Dependency Effects in Explaining Income Inequality in the Global Economy: A Cross-National Analysis, 1975-1995." Journal of World-Systems Research 8: 30-59.

Bergh, Andreas. 2005. "On the Counterfactual Problem of Welfare State Research: How Can We Measure Redistribution?', European Sociological Review 21(4): 345-57.

Bollen, Kenneth A. 1983. "World System Position, Dependency, and Democracy: The CrossNational Evidence.” American Sociological Review 48: 468-79.

\footnotetext{
${ }^{16}$ Indeed, both simultaneous equation and hybrid panel models are now one step simpler because our results suggest that the Snyder and Kick measure is the most robust predictor of income inequality among available measures of world-system position a-priori.
} 


\section{WITHIN-COUNTRY INEQUALITY AND THE WORLD-SYSTEM 304}

. 1987. "World System Status and Development Status: Overfitting or Proxy Variables." International Journal of Comparative Sociology 28: 75-9.

Bollen, Kenneth. A. and Jennie E. Brand. 2010. "A General Structural Equation Model for Panel Data with Random and Fixed Effects." Social Forces: Forthcoming.

Bollen, Kenneth A. and Stephen J Appold. 1993. "National Industrial Structure and the Global System.” American Sociological Review 58: 283-301.

Bonferroni, Carlo E. 1936. "Teoria statistica delle classi e calcolo delle probabilit ‘a." Pubblicazioni del $R$ Istituto Superiore di Scienze Economiche e Commerciali di Firenze 8: 3-62.

Borgatti, Stephen P, and Martin G. Everett. 1999. "Models of Core/Periphery Structure." Social Networks 21: 375-95.

Bornschier, Volker and Ballmer-Cao, Thanh-Huyen. 1979. "Income Inequality: A Cross National Study of the Relationship Between MNC-Penetration, Dimensions of the Power Structure and Income Distribution." American Sociological Review 44: 438-506.

Bornschier, Volker, Christopher Chase-Dunn, and Richard Rubinson. 1978. "Cross-National Evidence of the Effects of Foreign Investment and Aid on Economic Growth and Inequality: A Survey of Findings and a Reanalysis." American Journal of Sociology 84: 651-83.

Bornschier, Volker and Christopher Chase-Dunn. 1985. Transnational Corporations and Underdevelopment. New York: Praeger.

Boyd, John, William Fitzgerald, Matthew C. Mahutga and David A. Smith. 2010. "Computing Continuous Core/Periphery Structures for Social Relations Data Using MINRES SVD." Social Networks 32(2): 125-137

Bradley, David, Evelyne Huber, Stephanie Moller, Francois Nielsen, and John D. Stephens. 2003. "Distribution and Redistribution in Postindustrial Democracies." World Politics 55:193228.

Bunker, Stephen and Paul Ciccantell. 1995. "Restructuring Space, Time and Competitive Advantage in the World-Economy: Japan and Raw Materials Transport after World War II." In David A. Smith and Joseph Borcoz (eds.) A New World Order? Global Transformations in the Late Twentieth Century. Westport: Greenwood Press.

Chase-Dunn, Christopher. 1998. Global Formation: Structures of the World-Economy. Lanham, MD: Rowan \& Littlefield Publishers, Inc.

Chase-Dunn, Christopher and Peter Grimes. 1995. "World-Systems Analysis." Annual Review of Sociology 21: 387-417.

Clark, Robert. 2010. "World-System Mobility and Economic Growth, 1980-2000." Social Forces 88(3): 1121-51.

Clark, Rob and Jason Beckfield. 2009. "A New Trichotomous Measure of World-System Position using the International Trade Network." International Journal of Comparative Sociology 50: 5-38.

Peter Evans. 1979. "Beyond Core and Periphery: A Comment on the World System Approach to the Study of Development." Sociological Inquiry 49(4)15-20.

FAOUN. 2009. FAOSTAT Online Statistical Service. Rome: FAOUN. http://faostat.fao.org.

Farmer, Paul. 2004. "Who Removed Aristide?" London Review of Books, April 15. 
Galbraith, James K. and Hyunsub Kum. 2005. "Estimating the Inequality of Household Incomes: A Statistical Approach to the Creation of a Dense and Consistent Global Data Set." Review of Income and Wealth 51: 115-43.

Green, William H. 2000. Econometric Analysis, $4^{\text {th }}$ ed. Prentice Hall: New Jersey.

Halaby, Charles. 2004. "Panel Models in Sociological Research: Theory into Practice." Annual Review of Sociology 30: 507-44.

Heston, Alan, Robert Summers and Bettina Aten. 2006. Penn World Table Version 6.2. Center for International Comparisons of Production, Income and Prices at the University of Pennsylvania.

Hewitt, Christopher. 1977. "The Effect of Political Democracy and Social Democracy on Equality in Industrial Societies: A Cross-National Comparison." American Sociological Review 42: 450-64.

Kentor, Jeffrey. 2000. Capital and Coercion. New York, NY: Garland.

Kentor, Jeffrey, Andrew K. Jorgenson, Daniel Poole and Marti Morris. 2010. "Measuring the World-System." Paper presented at the Annual Meetings of the American Sociological Association, August, Atlanta, USA.

Kick, Edward L. and Byron L. Davis. 2001. "World-System Structure and Change: An Analysis of Global Networks and Economic Growth Across Two Time Periods." American Behavioral Scientist 44(10): 1567-78.

Kollmeyer, Christopher. 2009. "Explaining Deindustrialization: How Affluence, Productivity Growth and Globalization Diminish Manufacturing Employment." American Journal of Sociology 114: 1644-74.

Kuznets, Simon. 1955. "Economic Growth and Income Inequality." The American Economic Review 45: 1-28.

Lee, Cheol-Sung. 2005. "Income Inequality, Democracy, and Public Sector Size." American Sociological Review 70: 158-81.

Lee, Cheol-Sung, Francois Nielsen, and Arthur S. Alderson. 2007. "Income Inequality, Global Economy and the State." Social Forces 86: 77-111.

LIS. 2008. Luxembourg Income Study Database. Available at http://www.lisproject.org/techdoc.htm

Lloyd, Paulette, Matthew C. Mahutga, Jan De Leuw. 2009. "Looking Back and Forging Ahead: Thirty Years of Social Network Research on the World-System." Journal of WorldSystems Research 15: 48-85.

Mahoney, James. 2004. "Revisiting General Theory in Historical Sociology." Social Forces 83(2): 459-89.

Mahutga, Matthew C. 2012. "When do Value Chains go Global? A Theory of the Spatialization of Global Value Chains." Global Networks: Forthcoming. . 2006. "The Persistence of Structural Inequality?: A Network Analysis of International Trade, 1965-2000." Social Forces 84: 1863-89.

Mahutga, Matthew C and David A. Smith. 2011. "Globalization, the Structure of the WorldEconomy and Economic Development." Social Science Research: 40(1): 257-72. .

McMichael, Phillip. 1996. Development and Social Change: A Global Perspective. Thousand Oaks, CA: Pine Forge Press.

Muller, Edward N. 1988. "Democracy, Economic Development, and Income Inequality." American Sociological Review 53: 50-68. 


\section{WITHIN-COUNTRY INEQUALITY AND THE WORLD-SYSTEM 306}

Nemeth, Roger J. and David A. Smith. 1985. "International Trade and World-System Structure: A Multiple Network Analysis." Review 8: 517-60.

Nielsen, Francois. 1994. "Income Inequality and Industrial Development: Dualism Revisited." American Sociological Review 59: 654-77.

Nolan, Patrick D. 1983. "Status in the World System, Income Inequality, and Economic Growth." American Journal of Sociology 89: 410-19.

O'Hearn, Denis. 1994. "Innovation and the World-System Hierarchy: British Subjugation of the Irish Cotton Industry, 1780-1830.” American Journal of Sociology 100: 587-621.

Plumper, Thomas and Vera E. Troeger. 2007. "Efficient Estimation of Time-Invariant and Rarely Changing Variables in Finite Sample Panel Analyses with Unit Fixed Effects." Political Analysis 15: 124-39.

Prais, S and C. Winsten. 1954. "Trend Estimation and Serial Correlation." Cowles Commission Discussion Paper No. 383. Chicago.

Rogers, William. H. 1993. "Regression standard errors in clustered samples." Stata Technical Bulletin 13: 19-23.

Rubinson, Richard. 1976. "The World-Economy and the Distribution of Income within States." American Sociological Review 41: 638-59.

Rubinson, Richard and David Quinlan. 1977. "Democracy and Social Inequality: A Reanalysis." American Sociological Review 42: 611-23.

Rueda, David and Jonas Pontusson. 2000. "Wage Inequality and varieties of Capitalism." World Politics 52: 350-83.

Simpson, Miles. 1990. "Political Rights and Income Inequality: A Cross-National Test." American Sociological Review 55: 682-93.

Skocpol, Theda. 1977. "Wallerstein's World Capitalist System: A Theoretical and Historical Critique." American Journal of Sociology 82: 284-315.

Smith, David A. and Douglass R. White. 1982. "Structure and Dynamics of the Global Economy: Network Analysis of International Trade 1965-1980.” Social Forces 70: 857-93.

Snyder, David and Edward Kick. 1979. "Structural Position in the World System and Economic Growth, 1955-1970: A Multiple-Network Analysis of Transnational Interactions." The American Journal of Sociology 84:1096-1126.

Solt, Frederick. 2009 "Standardizing the World Income Inequality Database." Social Science Quarterly 90: 231-242.

van Rossem, Ronan. 1996. "The World System Paradigm as General Theory of Development: A Cross-National Test." American Sociological Review 61(3): 508-527.

Wallerstein, Immanuel. 1989. The Modern World System III: The Second Era of Great Expansion of the Capitalist World Economy, 1730-1840s. New York, NY: Academic Press. . 1974.. The Modern World System I: Capitalist Agriculture and the Origins of the European World Economy in the Sixteenth Century. New York, NY: Academic Press.

Weede, Erich and Joachim Kummer. 1985. "Some Criticism of Recent Work in World System Status, Inequality, and Democracy." International Journal of Comparative Sociology 26: 135-148.

White, Harrison C. and Ronald L. Breiger. 1975. "Pattern Across Networks." Trans-Action 12: 68-73.

Wooldridge, Jeffrey M, 2002. Econometric Analysis of Cross Section and Panel Data. Cambridge: MIT Press 
307 JOURNAL OF WORLD-SYSTEMS RESEARCH

World Bank. 2003. World Development Indicators [CD ROM]. Washington DC: World Bank. 